\title{
RELAÇÕES DE GÊNERO E DIVERSIDADE SEXUAL NAS CIÊNCIAS HUMANAS E SOÇIAIS: APROXIMAÇÕES TEÓRICAS E LEVANTAMENTO DE GRUPOS DE PESQUISA NO BANCO DE DADOS DO CNPq
}

\author{
Silvani dos Santos Valentim ${ }^{1}$ \\ Luna Oliveira ${ }^{2}$
}

As instituições de ensino brasileiras precisam engajar, de forma cada vez mais comprometida, com o desenvolvimento de ações, programas e políticas institucionais que promovam a equidade de gênero e a inclusão social e educacional, sempre em defesa da diversidade humana (VALENTIM, 2014). É importante destacar que as desigualdades raciais e de gênero são duas variáveis capazes de explicar e exemplificar as desigualdades estruturantes da sociedade brasileira.

No ano de 2012, o Centro Federal de Educação Tecnológica de Minas Gerais (CEFET-MG) institucionalizou a Coordenação-Geral de Relações ÉtnicoRaciais, Inclusão e Diversidades (CGRID) ${ }^{3}$. A escrita deste trabalho foi motivada pela experiência desta Coordenação no desenvolvimento das ações institucionais especificamente vinculadas às questões de gênero e diversidade sexual. Este estudo objetivou: acumular maiores informações a respeito da temática de gênero e diversidade sexual por meio da realização de levantamento do Diretório dos Grupos de Pesquisas do Conselho Nacional de Pesquisa (CNPq), que atualmente é intitulado: Conselho Nacional de Desenvolvimento Científico e Tecnológico; contribuir com a delimitação da temática a ser estudada; orientar sobre as lacunas

\footnotetext{
${ }^{1}$ CEFET-MG - Professora Associada, Coordenadora-Geral de Relações Étnico-Raciais, Inclusão e Diversidades da mesma instituição. silvanisvalentim@des.cefetmg.br

${ }^{2}$ CEFET-MG - Acadêmica do Curso de Letras, da Coordenação-Geral de Relações Étnico-Raciais, Inclusão e Diversidades da mesma instituição.

${ }^{3}$ A CGRID tem sob sua responsabilidade três Núcleos, que tem suas respectivas coordenadoras: o Núcleo de Apoio a Pessoas com Necessidades Educacionais Específicas - NAPNE; Núcleo de Pesquisa e Estudos Afro Brasileiros - NEAB; e o Núcleo de Estudos sobre Gênero e Diversidades NEGED. Seus objetivos incluem: proposição de políticas, programas e projetos que promovam a inclusão educacional e a equidade em uma perspectiva de gênero, etnia e classe social; Desenvolver atividades, programas e projetos que tratem da temática das Relações de Gênero, Orientação Sexual e Educação das Relações Étnico-Raciais. Registrar, monitorar, pesquisar, propor e até mesmo gerenciar iniciativas e ações institucionais referentes às ações afirmativas, relações de gênero e orientação sexual, inclusão educacional, sucesso acadêmico e realização educacional.
} 
temáticas a serem preenchidas e delimitar as áreas que suscitam interesse de aprofundamento futuro.

No Brasil, a exemplo de muitos outros países, as mulheres e as comunidades LGBTs têm sido historicamente alijadas dos espaços sociais e das instâncias de decisão, assim como do acesso a bens e serviços, sobretudo em áreas rurais e nas regiões interioranas do País. O desenvolvimento de ações centradas nas diversidades tem sido um desafio constante para as instituições de ensino no Brasil, seja na educação básica, no ensino superior ou na pós-graduação. Vale destacar, antes de qualquer análise, que o histórico de negação de direitos a diversos grupos na sociedade brasileira constitui a base de sua desigualdade estrutural. Deve-se levar em conta que a conquista de direitos de pessoas e grupos que sempre foram marginalizados - mulheres, negras e negros, LGBTs, dentre outros, ainda é bem recente e incompleta em vários aspectos.

Pesquisa realizada por uma das autoras deste artigo revela que em instituições públicas de ensino superior de todo país o aumento, ainda que tímido, do número de discentes que pertence a determinados seguimentos sociais ou grupos específicos. Podemos citar os negros (as), quilombolas, pessoas de comunidades tradicionais, pessoas de orientação LGBT, mulheres em cursos tradicionalmente frequentados por homens; feministas, dentre outros segmentos (VALENTIM, 2015).

\section{RELAÇÕES DE GÊNERO E DIVERSIDADE SEXUAL}

Raça, gênero e sexualidade são constituintes que compõem a identidade do sujeito. O gênero vai além de separar corpos em femininos ou masculinos, é uma construção social relacionada à distinção e hierarquia masculino e feminino, abrangendo dimensões econômicas e políticas (CARVALHO, 2010). A sexualidade não pode ser entendida fora das questões de gênero. Além de ser uma questão pessoal, social e política, sexualidade é aprendida e construída ao longo da vida e envolve os múltiplos discursos sobre sexo: rituais, linguagens, fantasias e representações simbólicas (LOURO, 2000; 2011).

A cultura é dinâmica e constantemente reinventa tradições e significados. Neste sentido, identidade de gênero (a maneira como alguém se sente e se apresenta para si e para as demais pessoas como masculino ou feminino - a forma 
como nos reconhecemos e desejamos que as outras pessoas nos reconheçam) é o resultado de uma construção cultural, social e simbólica e não de uma determinação do sexo biológico. Os papéis sociais de homens e mulheres, assim como a identidade sexual e de gênero definem-se pela cultura e nos contextos socioculturais (LOURO, 1997).

Este artigo pode ser considerado uma práxis (ação e reflexão) nesse espaço de gestão da inclusão e da diversidade no interior da Diretoria de Extensão. As reflexões aqui apresentadas envolvem o entendimento que papéis sociais influenciam a maneira como a identidade é construída (HALL, 2005).

Ao longo do estudo algumas indagações revelaram-se pertinentes. Por exemplo: iniciativas no âmbito da pesquisa, ensino e extensão incluem em seus eixos temáticos e linhas programáticas temas como relações étnico-raciais, gênero e diversidade sexual? Grupos de pesquisa representam a construção de uma multiplicidade de saberes, alicerçados tanto nos conhecimentos acadêmicos quanto nos conhecimentos que emanam das experiências e processos de aprendizagem de comunidades LGBTs?

Relações de gênero devem ser pesquisadas e contextualizadas. $O$ sistema de estratificação social brasileiro está alicerçado em processos em que a cor da pele e raça, assim como a sexualidade e sexo funcionam como mecanismos de segregação e estratificação social. Para garantirmos as transformações sociais e educacionais é necessário, sobretudo, cambiar mentalidades, ações e os cânones que orientam as pesquisas no campo das ciências humanas e sociais.

É importante considerar todas as mudanças que ocorreram nas últimas décadas em relação ao sentimento e à vivência da sexualidade pelas pessoas, em especial as mais jovens, que passaram gradativamente a encarar essa de questão de forma aberta, passando de uma esfera particular, quase proibitiva de se dizer publicamente, a uma esfera em que a sexualidade é assumida como possível de ser vivenciada na arena pública, como uma experiência que engendra novas configurações familiares e institucionais em que a demanda de pessoas transexuais e transgêneras pela utilização legal do nome social, por exemplo, constitui um direito.

Sendo a identidade estabelecida pelas diferenças existentes, o que somos é muitas vezes definido em relação ao que não somos (MOREIRA; CÂMARA, 2010), ou em relação ao que a sociedade não gostaria que as pessoas 
fossem. Deste modo é possível imaginar que uma adolescente negra, homoafetiva/homossexual, do gênero feminino, da classe trabalhadora e de uma religião de matriz africana tenda a ser discriminada de maneira incisiva e sem retóricas ou eufemismos.

No Brasil, os Parâmetros Curriculares Nacionais colocam uma importante orientação aos professores no que concerne ao tema. Essas orientações visam, sobretudo, permitir ao alunado encontrar na escola um espaço de informação e de formação, no que diz respeito às questões referentes ao seu momento de desenvolvimento e às questões que o ambiente coloca (BRASIL, 1997). No caso dos (as) alunos (as) do ensino fundamental, é no estímulo à reflexão a partir da problematização e debate das diversas temáticas atuais da sexualidade (BRASIL, 1997).

No Ensino Superior ocorre, por parte dos discentes, uma reflexão mais madura sobre o tema, pelo fato de que os (as) estudantes que acessam esse nível de ensino já estão geralmente na fase adulta, ou próxima dela. Também contribui para a discussão a própria natureza das Instituições de Ensino Superior que se voltam, nas últimas décadas - a partir de um momento histórico de abertura política e consolidação democrática da sociedade brasileira - para a produção do conhecimento, baseado na tríade ensino, pesquisa e extensão.

\section{METODOLOGIA}

Instrumentos utilizados para a realização do estudo incluíram revisão bibliográfica e levantamento de Núcleos e Grupos de Pesquisa sobre a temática de gênero e diversidade sexual, registrados no CNPq. A Pesquisa no portal eletrônico do Diretório de Grupos de Pesquisa do CNPq realizou-se por meio de descritores para consulta parametrizada, bem como dos definidores relativos às áreas do conhecimento, de acordo com definição do CNPq. No tópico seguinte, apresentamos o resultado deste levantamento.

\section{RESULTADOS E DISCUSSÃO}

Os descritores utilizados revelaram as seguintes informações: Relações de gênero (282 Grupos de Pesquisa); Diversidade sexual e relações de gênero (2 
Grupos de Pesquisa); Relações de gênero e diversidade sexual (3 Grupos e Pesquisa); Diversidade sexual (65 Grupos de Pesquisa).

Verificou-se, assim, que existe um significativo número de grupos registrados no CNPq. Na maioria dos grupos a abordagem é interdisciplinar, relacionando relações de gênero e diversidade sexual com outras áreas do conhecimento - História, Geografia, Ciências Sociais, Linguística, Direito, Psicologia, etc. - gerando conhecimentos específicos de maior qualidade. No caso específico do CEFET-MG, estão registrados os Grupos Igualdade e Relações de Gênero em áreas de Ciência e Tecnologia (GECITEC), bem como o Núcleo de Estudos sobre Gênero e Diversidade Sexual (NEGED).

Os grupos registrados no CNPq incluem instituições de ensino superior de todo o Brasil, com destaque para as instituições públicas. É importante frisar, também, a alta concentração desses grupos em IEs localizadas nos estados da região Centro-sul do Brasil. É importante considerar que os Estados da região Nordeste já contam com uma quantidade significativa desses núcleos em suas IEs.

\section{À GUISA DE CONCLUSÃO}

O levantamento dos Grupos e Núcleos de Pesquisa aponta para uma multiplicidade de temas e abordagens, assim como foi possível vislumbrar uma constelação de pesquisadores (a) interessados (as) na temática de gênero e diversidade sexual. Apresentamos nos apêndices I, II, III e IV o resultado deste levantamento.

Este trabalho está em andamento e objetivou-se com esta primeira etapa do levantamento construir um panorama geral sobre os grupos de pesquisa, atualizados no CNPq, sobre relações de gênero e diversidade sexual a partir das informações extraídas do Diretório dos Grupos de Pesquisa. Além de aprofundar as informações encontradas, pretende-se expandir tal levantamento para outros descritores como mulheres, LBGTs e transexualidade, por exemplo. Pretende-se também, em pesquisa já iniciada, realizar uma análise mais aprofundada sobre as linhas de pesquisa dos grupos. 


\section{REFERÊNCIAS}

BRASIL. Ministério da Educação. Parâmetros Curriculares Nacionais. 1997.

CARVALHO, Marília Pinto de. Gênero na sala de aula: a questão do desempenho escolar. In: MOREIRA, Antônio Flávio; CANDAU, Vera Maria (Orgs). Multiculturalismo: Diferenças Culturais e Práticas Pedagógicas. 4. ed; Petrópolis, RJ; Vozes, 2010. Cap. 4; p. $90-124$.

HALL, Stuart. A identidade cultural na pós modernidade. 10. ed. Rio de Janeiro: DP\&A, 2005.

LOURO, Guacira Lopes. Gênero, sexualidade e educação: uma perspectiva pósestruturalista. 12 ed. Petrópolis, Vozes, 2011.

LOURO, Guacira Lopes. Pedagogias da sexualidade. In: LOURO, Guacira Lopes (Org). O corpo educado: pedagogias da sexualidade. 2 ed. Belo Horizonte, Autêntica, 2000.

MOITA LOPES, Luiz Paulo. Sexualidades em sala de aula: discurso, desejo e teoria queer. In: MOREIRA, Antônio Flávio; CANDAU, Vera Maria (Orgs). Multiculturalismo: Diferenças Culturais e Práticas Pedagógicas. 4 ed; Petrópolis, RJ; Vozes, 2010. Cap. 5; p. 125 - 148.

MOREIRA, Antônio Flávio B.; CÂMARA, Michele J. Reflexões sobre currículo e identidade: implicações para a prática pedagógica. In: MOREIRA, Antônio Flávio; CANDAU, Vera Maria (Orgs). Multiculturalismo: Diferenças Culturais e Práticas Pedagógicas. 4 ed; Petrópolis, RJ; Vozes, 2010. Cap. 2; p. 38 - 66.

VALENTIM, Silvani S. Interculturalidade, multiculturalismo e produção do conhecimento no contexto educacional. In: TONINI, A M; OLIVEIRA, B. R (Orgs.). Coordenação Pedagógica e Formação Continuada de Professores. Juiz de Fora: Editar, 2015.

VALENTIM, Silvani S.; PINHEIRO, Karine L. M. Ações afirmativas de base racial na educação pública brasileira. Educação \& Tecnologia, v. 20, n 1. 2014. 